\title{
Conceptualizing Agri Nutri Information Framework for Mitigating Nutrition Security Challenges of India: A much-needed approach for Nutrition Security
}

\author{
Rubeka Idrishi \\ School of Agro and Rural Technology, Indian Institute of Technology, Guwahati- Assam, India 781039 \\ Corresponding author e-mail: rubeka3155@gmail.com
}

(Received: 15/05/2021; Revised: 15/09/2021; Accepted: 25/10/2021)

\begin{abstract}
India being an Agrarian economy relies mostly on its agricultural outputs every year, but the uncertainty in the agricultural system of India is very high. A large population (majorly rural) is undernourished, from which the tackle history has been very slow and is continuing which continuously questions about the nutritional security of India. Besides various efforts made by the Indian government, policymakers, and technology-driven approach there lies a huge gap between effective interventions to join these two nodes which are agriculture and nutrition. Understanding the importance of the Agri-Nutri Framework for diet improvement, generating incomes, maternal and child health, and care practices this paper collectively maps all the existing evidence along with agriculture- nutrition frameworks/ pathways studied till now. Thus, this paper gives a comprehensive and conceptually designed framework by delineating pathways between agriculture and nutrition, pathways of the nutritional and health impacts, and various impacts of the same on food policies, farm production, farm incomes, food prices, and agriculture-gender linkages. Keywords: Agriculture, Nutrition Security, Framework, Pathway, Policy, SDG.
\end{abstract}

\section{INTRODUCTION}

There has been an increasing push globally towards achieving the Sustainable Development Goals (SDGs) especially the ones which are related to food security and nutrition and it is equally important as well as others because recent literature does emphasize the importance of identifying different frameworks and pathways which connects agriculture and nutrition and are important for better nutritional outcomes. IFPRI (Das, Sharma, \& Babu, 2017) studied and examined the efforts of Indian states towards SDG and highlighted that there are various disconnects and lack of linking connections in the food and nutritional security indicators. It was suggested in the same that to attain food and nutritional security by 2030 , evidence-based policy framing is needed. As concluded by (Mayne \& Johnson, 2016) the development of various frameworks and pathways allows the following improvements in the existing system:

Better designed interventions

Strong and more realistic monitoring

An ongoing tool for adaptive management

A strong base for demonstrating accomplishments.

An overview of pathways linking agriculture \& nutrition

All the pathways linking agriculture and nutrition follows a long path rather than short and quick because of the complexity of agricultural investments, interventions, and the key components which covers combinations of price, access to market, health and nutritional services, incomes, women empowerment, improved agricultural production and practices, dietary diversity, household beliefs and behaviours, storage and processing methods (RDW et al., 2018).

A Bangladesh-based study by (Headey \& Hoddinott, 2016b) explored agriculture and nutrition linkages in Bangladesh by outlining a model which emphasized child nutrition outcomes, productivity, and food staples. They emphasized on the increasing concern that with rapid growth in yield and calorie availability the diversification is sluggish despite relying on imports for dietary diversification.

Mapping the degree of the present agricultural researches for the improvement of nutrition to identify gaps as there are comparatively less researches on studying indirect impacts of nutrition and agriculture. wherein more efforts in terms of research and implementation are the need of the hour. Along with diversification there lies gaps too, (Turner et al., 2014) studied the current research landscape with a geographic focus on sub-Saharan Africa in terms of agriculture for improved nutrition and identified that many research projects cover a wide range of studies focussed on just children's and women, urban consumers, nutritionrelated non communicable diseases. 
There is very little work on the cost-effectiveness of agricultural interventions. Therefore, research inv estments for broader engagement of researchers and disciplines are needed in developing approaches lay and analysing agricultural programs for improved nutrition. There are various steps which has to be taken by every country to create a network and repository of data which amalgamates nutrition, agriculture and policy interventions.

For creating a global data ecosystem that benefits everyone, a wide range of stakeholders must be included in the conversations. (Musker \& Schaap, 2018) formed the Global Open Data in Agriculture and Nutrition (GODAN) initiative which works with a network above 500 partner organizations of agriculture and nutrition committed over open data sharing (Jonquet et al., 2016) during their development of Agro Portal which is an open repository for agricultural and nutritional data emphasised the need of the same as they quoted that there exists a need of a one-stop node for all agronomical, environmental and food related ontologies. Above 800 farm households in Kenya was studied by (Jackering et al., 2019) for characteristics of agricultural and nutrition information networks within farmer groups And the results highlighted that very limited nutrition information is exchanged within farmer groups, less exchanged between men and women and the majority of the information flows through the existing agricultural information links, group leaders and persons living in central locations. Thus, agriculture extension systems must be effective enough to do so and the heterogeneities should be encountered at micro level because the greater the equality share and neutral acceptance of society in terms of caste, creed, gender, race and communities, greater are the chances of improvement of nutritional security. (Fry et al., 2020) took a study hypothesizing the same and highlighted that encountering heterogeneity between gender equity and food security at householdlevel is needed to establish the impact of gender equity on nutrition outcomes across contexts. Therefore, these differences in characteristics and network structure should be taken into account while designing nutritionsensitive extension programs. (Harris-fry \& Krishnan, 2020) in their study trial performed at Odisha (An Indian state) highlighted that agriculture interventions must consider women's decision-making, land quality, and implications for women's workload in their design of 'nutrition-sensitive' agricultural interventions. In studying pathways linking women in agriculture and nutrition the lack of quality evidence acts as a barrier. These are because of the methodological challenges, complexity of pathways and indirect relationships in gender based agrarian system and nutritional programmes (Rao, et al., 2018)

Since these interventions challenge the world for achieving SDGs to connect food production and consumption in a way that matches local contexts and enables everyone to enjoy a healthy diet that is produced sustainably and contributes to the other SDGs but various countries find it tough to achieve because of the underlying gaps and missing middles between two nodal coordinates. (Jl et al., 2019) made an effort to identify a Missing Middle between food production and consumption, and between globally defined goals and local implementation practices that may hinder progress towards SDG 2 and found that there are missing middles at global, national and local levels between SDG targets, agricultural policies and agriculture and nutrition. Hence, it is important to start addressing the Missing Middle by collaborating with relevant stakeholders in specified cases.

The key findings in all the studies discussed here is a general lack of uniformity in food security status along the pathways in different indicators. The heterogeneities imply that while designing an intervention a singular focus is inappropriate because connecting all possible dots of agriculture-to-nutrition pathways and linkages is important. In a country like India this explains that why food security policies have failed to reduce the high rates of malnutrition for decades and failed to help the country attain the its Millennium Development Goals (MDGs) (Das et al., 2017). In a study conducted by (Poole et al., 2018) in Afghanistan to study the various agricultural and nutritional practices, policies and their coherence highlighted that the gaps were found in human and financial resources, policy formulation, knowledge management, focus, and in inhibiting the national strategies towards nutrition-sensitivity. Integrating agriculture and nutrition policies requires explicit leadership from the government. Hence, the policy approaches need to be more practical which should consider long and short-term indicators in order to attain the SDGs.

Taking example from the pathways followed by China, which in just three decades from 1980s to 2000 have achieved tremendous improvement in food security as well as rural and urban growth with a GDP growing at 10 percent annually. Following were the driving factors in achievement its self-sufficiency (Huang \& Rozelle, 2010):

Allowing an "open-door" agricultural policy and allied sectors facilitates the shift from a rural, agriculture-based economy to one based on urban industry and services.

Increasing International trade and foreign direct investment was the other engine of economic growth and structural shifts to more competitive sectors.

China made food security its primary aim with agriculture specific policies to macroeconomic policy, China is now able to feed its growing population from limited natural resources and developed itself as an exporter of food and agricultural products with increase in per capita availability of food to its citizens also and China after the 2000s decided that it's rural/agricultural sector needed enhancement and thus it initiated investing in lower communities in terms of roads, public education irrigation, nutrition, drinking water and health services, and direct subsidy programmes. 
From this study it can be understood that commercialization of agriculture and nutritional commodities are also important in order to increase the impact of policy interventions at small stakeholder level. (Ogutu, Theda, \& Qain, 2020) on assessing the effects of commercialisation in Kenya on household food security and dietary quality highlighted that commercialisation contributes to increased nutrients and higher incomes from purchased foods, but it does not reduce the consumption of nutrients from own-produced foods. Enhancing market access is important not only for rural economic growth, but also for making smallholder agriculture more nutrition-sensitive. (Hide, Allen, \& Bourke, 1992) in their study done on addressing some issues related to agriculture and nutrition system highlighted that a high level of malnutrition and a rapidly increasing level of food imports was a result of lack of agriculture and nutritional linkages in the country hence, the policy plays dual aim of improving nutritional status and without increasing food imports.

Frameworks connecting agriculture to nutrition security

\begin{tabular}{|c|c|}
\hline $\begin{array}{l}\text { Framework developed/ } \\
\text { researched }\end{array}$ & Author and Year \\
\hline $\begin{array}{l}\text { Bridging factors on the } \\
\text { agriculture-to-nutrition } \\
\text { pathway }\end{array}$ & $\begin{array}{l}\text { (Das et al., 2017) } \\
\text { IFPRI }\end{array}$ \\
\hline $\begin{array}{l}\text { Food, agriculture, and } \\
\text { nutrition security framework }\end{array}$ & $\begin{array}{l}\text { (Das et al., 2017) } \\
\text { IFPRI }\end{array}$ \\
\hline $\begin{array}{l}\text { The linkages between yield } \\
\text { growth, dietary changes, and } \\
\text { nutrition outcomes in } \\
\text { Bangladesh }\end{array}$ & $\begin{array}{l}\text { (Headey \& } \\
\text { Hoddinott, 2016b) }\end{array}$ \\
\hline $\begin{array}{ll}\text { Conceptual framework for } \\
\text { research on agriculture for } \\
\text { improved nutrition }\end{array}$ & (Turner et al., 2014) \\
\hline $\begin{array}{l}\text { Framework on representation } \\
\text { of The Missing middle: } \\
\text { Connected action on } \\
\text { agriculture and nutrition } \\
\text { across } \\
\text { global, national and local } \\
\text { levels to achieve Sustainable } \\
\text { Development Goal } 2\end{array}$ & (J1 et al., 2019) \\
\hline $\begin{array}{l}\text { A generic A4NH- Agriculture } \\
\text { for Nutrition and Health } \\
\text { intervention impact pathway. }\end{array}$ & $\begin{array}{l}\text { (Mayne \& Johnson, } \\
\text { 2016) }\end{array}$ \\
\hline $\begin{array}{l}\text { Conceptual Framework for } \\
\text { the PoSHAN Study }\end{array}$ & (RDW et al., 2018) \\
\hline $\begin{array}{l}\text { Pathways from land size to } \\
\text { maternal body mass index } \\
\text { (BMI) diet diversity: } \\
\text { Estimations from potential } \\
\text { outcomes framework analysis }\end{array}$ & $\begin{array}{ll}\text { (Harris-fry } & \& \\
\text { Krishnan, 2020) } & \end{array}$ \\
\hline $\begin{array}{l}\text { Women's work as a mediator } \\
\text { between household socio- }\end{array}$ & (Rao et al., 2018) \\
\hline
\end{tabular}

\begin{tabular}{|l|l|}
\hline $\begin{array}{l}\text { economic status and food } \\
\text { security and nutrition. }\end{array}$ & \\
\hline $\begin{array}{l}\text { Gendered agriculture- } \\
\text { nutrition pathways. }\end{array}$ & $\begin{array}{l}\text { (Kadiyala, Harris, } \\
\text { Headey, Yosef, \& } \\
\text { Gillespie, 2014) }\end{array}$ \\
\hline $\begin{array}{l}\text { Agriculture, nutrition and the } \\
\text { Sustainable Development } \\
\text { Goals (SDGs). }\end{array}$ & $\begin{array}{l}\text { Adapted in (Poole et } \\
\text { al., 2018) from } \\
\text { Waage and Yap } \\
(2015) \text { and Poole, N. } \\
(2017) .\end{array}$ \\
\hline $\begin{array}{l}\text { Pathways between agriculture } \\
\text { and nutrition include } \\
\text { consumption of own } \\
\text { production, income and } \\
\text { women's empowerment }\end{array}$ & \& Batal, 2019) \\
\hline \multicolumn{2}{|c|}{} \\
\hline
\end{tabular}

\section{Insights of the above frameworks}

Bridging factors on the agriculture-to-nutrition pathway by (Das et al., 2017) representing IFPRI provided a framework with various pathways. There were three pathways which represents a disconnect between agriculture and nutrition, and how it can be overcome by adopting sustainable bridging mechanisms and other three pathways focused on the impact of the mother's health status and level of empowerment on the child's nutritional status, characterize the capabilities approach, along with the quality of drinking water, sanitation, and breastfeeding practices.

Food, agriculture, and nutrition security framework by (Das et al., 2017) was adapted and modified from two sources (Pinstrup-Andersen and Watson (2011); Babu, Gajanan, and Hallam (2017) which provides the conceptual background on various food security indicators pertaining to the different dimensions and pathways- including those measuring agricultural production, consumption expenditure, sanitation and hygiene facilities, care practices, health, and anthropometric status- across contemporary surveys, noting the sources of data. The input dimension was measured by indicators such as income and per capita availability and import of food grains. The level of education; access to clean drinking water, hygiene, and sanitation facilities; and childcare practices related to the process dimension. Indicators of the output dimension include a share of food in expenditures; consumption from the PDS; dietary diversity; and nutrient intake, measured in both calories and grams. Nutritional status was the outcome indicator.

The linkages between yield growth, dietary changes and nutrition outcomes in Bangladesh framework by (Headey \& Hoddinott, 2016a) presented a simplified framework for thinking through the various connections between rice productivity growth and changes in nutrition. At the top the focus was kept on policy-driven growth in rice yields (particularly the combination of agricultural $\mathrm{R} \& \mathrm{D}$, irrigation expansion and policies that affect other inputs, such as fertilizers). The next step in this framework was to consider how household level increases in incomes, rice consumption, and dietary 
diversity translate into improvements in the nutrition outcomes of young children, either via improvements in the diets of those children or in the diets of their mothers. This framework was designed to focus on the dietary aspects of agriculture-nutrition linkages (Headey \& Hoddinott, 2016a)

Conceptual framework for research on agriculture for improved nutrition by (Turner et al., 2014) represents the different pathways that link agricultural practices or interventions with nutrition-related outcomes either directly or indirectly. Change in nutritional status was marked as the endpoint and is placed centrally in this framework. Measurements of changes in "nutritional status" using anthropometry or biomarkers was the endpoint of a pathway of research, providing the strongest evidence that an agricultural practice or intervention affects nutrition. Changes in the "food environment" and "food consumption and intake" describe the pathway that links agricultural change to changes in nutritional status, but provide a different level of evidence of a change in nutritional status than its direct measurement.

Framework on representation of The Missing middle: Connected action on agriculture and nutrition across global, national and local levels to achieve Sustainable Development Goal 2 by (J1 et al., 2019) represented a simplified framework of the Missing Middle in SDG 2, i.e. the global-local axis and the food productionconsumption axis. There were two axes which relate to the distancing between global and local levels, and between producers and consumers of food, respectively the axes was used to elaborate what does the Missing Middle means for SDG 2 implementation.

A generic A4NH- Agriculture for Nutrition and Health intervention impact pathway by (Mayne \& Johnson, 2015) illustrated a generic impact pathway for an Agriculture for Nutrition and Health intervention, illustrating that typically A4NH does not deal directly with intended beneficiaries in a program or a policy intervention.

Conceptual Framework for the PoSHAN Study by (RDW et al., 2018) developed a conceptual framework to map out hypothesized causal pathways through which agriculture may improve food security and maternal and child nutrition, in part adapted from others that guided data acquisition at community, household and individual levels. The framework illustrated the potential for these complex pathways to interact positively or negatively at community, household and individual levels with mediating factors that include ecology and environment (e.g. water availability), markets, communications and infrastructure, household socioeconomic status (e.g. education, income, occupations), culture (e.g., caste, religion), sanitation and hygiene, food production/consumption patterns, and participation in agriculture extension, health, nutrition and other services, as well as dominant patterns of morbidity, women's status and lifestyle (e.g. smoking, women's workload), among other influences.
Pathways from land size to maternal body mass index (BMI) diet diversity: Estimations from potential outcomes framework analysis by (Harris-fry \& Krishnan, 2020) provided the total effect of land size on maternal BMI along with the effects of land size on the hypothesized mediators and the effects of the mediators on maternal BMI (adjusted for land size).

Women's work as a mediator between household socioeconomic status and food security and nutrition framework by (Rao et al, 2019) took forward the pathways framework to restate agriculture nutrition linkages with women's work not as a causal factor but a mediator between household poverty or socio-economic status and its food security and nutrition. This reframing allowed to focus on precisely those contextual issues in the mediation about which there remain gaps in knowledge and blind spots with respect to policies and interventions.

Gendered agriculture-nutrition pathways by (Kadiyala et.al, 2014) combined the approaches as UNICEF framework for nutrition. They organised their review along six distinctive pathways through which agriculture and nutrition could be connected which were food consumption, income, food prices women's consumption choices of food and non-food care time for children and women's own health. The study highlighted that consumption, care time and women's own health are highly interdependent on women's choice which is again governed by factors like food production, food prices, and income of the family.

Agriculture, nutrition and the Sustainable Development Goals (SDGs) framework by (Poole et al., 2018) adapted and modified two frameworks from Waage and Yap (2015) and Poole (2017: 10) which focussed on the three ring division. The close relationship between agriculture and nutrition and wider contextual factors was depicted by ordering the 17 Sustainable Development Goals which immediately concern people's health and welfare, with food and nutrition at the centre. In the second ring goals proximally related to agriculture and nutrition which plausibly have a less direct but important local impact was kept. Depicted outermost are the distal contextual and global issues, some implying governance, but most of which make a huge, sometimes less direct, contribution to agriculture and nutrition. This presentation emphasises how the agriculture and nutrition sectors are intertwined, and also how the wider environment of proximal and distal issues constitutes significant enabling - or disabling - factors.

Three pathways were highlighted in the findings reported by (Deaconu et al., 2019) in which Agroecology was recognized as a sustainable production strategy that is appropriate for the rural poor and the three key pathways agriculture and nutrition include consumption of own production, income and women's empowerment was found to be important factors for the improvement of farmer nutrition. 
Institutional Framework for Mitigating Nutrition Security Challenges of India

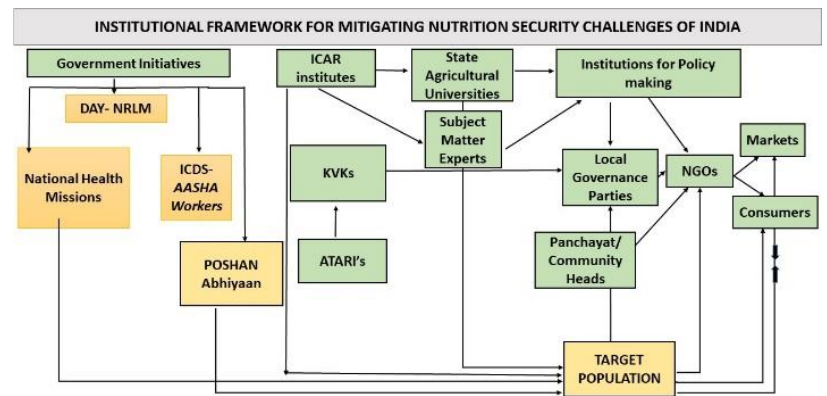

Figure 1: Institutional Framework for Mitigating Nutrition Security Challenges of India

This framework was conceptualized in order to provide a linking system in all the nodal bodies (which acts as an integral part for dissemination of services throughout India for nutrition security which can be used in public distribution systems (PDS) and other schemes like Integrated Child Development System (ICDS). This framework connects the various functional bodies of four operating nodal bodies which are 1. Initiatives taken by government such as Deendayal Antyodaya Yojana National Rural Livelihood Mission (DAY-NRLM), National Health Mission (NHM), Integrated Child Development System (ICDS)- POSHAN Abhiyaan (Government of India- Prime Minister's Overarching Scheme for Holistic Nutrition (POSHAN) or National Nutrition Mission) 2. Indian Council of Agricultural Research (ICAR) institutes, 3. State Agricultural Universities (SAUs) and 4. Institutions for Policy making. Latter three connects all the government initiatives (former) to functional bodies of these three nodes such as Krishi Vigyan Kendra's (KVKs), Agricultural Technology Application Research Institute (ATARI), subject matter experts, local governance parties, NGOs, markets, panchayat/ community heads and consumers to the targeted population.

DAY-NRLM was started as Aajeevika- NRLM a decade back in 2011 by the Ministry of Rural Development (MoRD), Government of India (GoI) which got renamed as DAY- NRLM in 2015. This scheme with the support of world bank aims at creating efficient and effective institutional platforms of the rural poor, enabling them to increase household income through sustainable livelihood enhancements and improved access to financial services. NHM of India encompasses its two submissions which are National Rural Health Mission (NRHM) and The National Urban Health Mission (NUHM). This scheme of Ministry of Health and Family Welfare (MoHFW) GoI aims at Health System Strengthening, Reproductive-Maternal- Neonatal-Child and Adolescent Health, and Communicable and Non- equitable, affordable \& quality health care services that are accountable and responsive to people's needs. ICDS is a flagship programme started by India in 1975 which is world's largest, unique and specifically designed for early childhood care, and development and pre and postnatal care of mothers. The ICDS Scheme offers a package of six services, viz. i. Supplementary Nutrition, ii. Pre-school non-formal education, iii. Nutrition \& health education, iv. Immunization, vi. Health check-up and Referral services where the last three services are related to health and are provided by MoHFW through NRHM \& Health system. The POSHAN abhiyaan/scheme was launched by GoI in 2018 as a action step towards the national nutrition strategy presented by NITI Aayog (A GoI body for strategic planning and manifestation) POSHAN is closely linked with ICDS because of its following strategic pilllars which very much aligns with the ICDS schemes: i. Use of technology (ICT) for real time growth monitoring and tracking of women and children and ii. intensified health and nutrition services for the first 1000 days. ICAR is linked with SAUs KVKs and ATARI which forms the institutional framework for agricultural research, dissemination and technology transfer to farmers and beneficiaries where SAUs, KVKs and ATARI acts as mini nodes which interconnects on district level in each state and governed by ICAR. The implementation of interlinked research bodies, policymakers, first hand service providers, agriculture, food systems, and nutritional programs is based on 'principles of mutual responsibility and coordinated action' where 'governments accept their obligations to their respective peoples in raising levels of nutrition and standards of living and to report to one another on the progress achieved (Byerlee \& Fanzo, 2019) because the evidences reveals gaps in knowledge of all the pathways and especially in the areas where agriculture is the major source of livelihood and women's role as intermediaries between agriculture and good nutrition and health within their household (Yosef et al., 2015).

\section{CONCLUSION}

Agri- Nutri frameworks are much needed layouts for providing the fingerprint between agriculture and nutrition in country specific settings, particularly with regards to the role of each and every sector. Various technological interventions should be made in the form of Interactive voice response systems, mobile apps, websites etc. and farmers, consumers, marketers should be made aware of such interventions and its usage because the lack of awareness of existence of such interventions for the welfare of themselves acts as one of the huge gaps in the system. They help in addressing nutrition-related outcomes, dietary diversity, heterogeneity and evaluating the impact of agricultural production systems and development initiatives. There are concerns for agri-food system is organization and the 
actions of economic agents within it for the environment, exposure of populations to biological, chemical, and/or physical hazards, livelihood of the poor, welfare of animals, sustainability of rural communities, and so on. A well-designed framework identifies and measures these impacts and defines all the viable ways in which they might be addressed are made easy by the variety and complexity of agri-food systems globally, keeping the inherent economic and political interests that tend to sustain the status quotient into account.

\section{REFERENCES}

Babu, S., S. N. Gajanan, and J. A. Hallam. 2016. Nutrition Economics: Principles and Policy Applications. Amsterdam: Academic Press.

Byerlee, D., \& Fanzo, J. 2019. The SDG of zero hunger 75 years on : Turning full circle on agriculture and nutrition. Global Food Security, 21(February), 52-59. https://doi.org/10.1016/j.gfs.2019.06.002

Das, M., Sharma, A., \& Babu, S. C. (2017). Pathways from agriculture to nutrition in India : Implications for sustainable development goals IFPRI Discussion Paper 01649 Pathways from Agriculture to Nutrition in India Implications for Sustainable Development Goals Mousumi Das Suresh Chandra Babu Di, (June).

Deaconu, A., Mercille, G., \& Batal, M. 2019. The Agroecological Farmer's Pathways from Agriculture to Nutrition: A Practice-Based Case from Ecuador's Highlands. Ecology of Food and Nutrition, 58(2), 142-165.

https://doi.org/10.1080/03670244.2019.1570179

Fry, H. H.-, Nur, H., Shankar, B., Zanello, G., Srinivasan, C., and Kadiyala, S. 2020. The impact of gender equity in agriculture on nutritional status, diets, and household food security: a mixed- - methods. Systematic review, (March). https://doi.org/10.1136/bmjgh-2019-002173

Harris-fry, H., \& Krishnan, S. 2020. Agricultural and empowerment pathways from land ownership to women' $s$ Agricultural and empowerment pathways from land ownership to women' $\mathrm{s}$ nutrition in India, (March).

https://doi.org/10.1111/mcn.12995

Headey, D. D., \& Hoddinott, J. 2016a. Agriculture, nutrition and the green revolution in Bangladesh. Agricultural Systems, 149, 122-131. https://doi.org/10.1016/j.agsy.2016.09.001

Headey, D. D., \& Hoddinott, J. 2016b. Agriculture, nutrition and the green revolution in Bangladesh. AGSY, 149, 122-131.

https://doi.org/10.1016/j.agsy.2016.09.001

Henson, S. 2015. Global Challenges : Food, Agriculture and Nutrition, 20-21.

Hide, R., Allen, B., and Bourke, R. M. 1992. Agriculture and nutrition in Papua New Guinea: Some issues.

Huang, J., \& Rozelle, S. 2010. Agricultural Development and Nutrition: the Policies behind China's Success, (June 2014).
Jackering, L., Godecke, T., \& Wollni, M. 2019. Agriculture - nutrition linkages in farmers' communication. The Journal of International Association of Agricultural Economists, 50(October), 657-672. https://doi.org/10.1111/agec.12516

Jl, L., Giller, K. E., Oosterveer, P., Brouwer, I. D., and Janssen, S. 2019. The Missing Middle: Connected action on agriculture and nutrition across global, national and local levels to achieve Sustainable Development Goal 2 The Missing Middle: Connected action on agriculture and nutrition across global, national and local le. Global Food Security, 24(November), 100336. https://doi.org/10.1016/j.gfs.2019.100336

Jonquet, C., Toulet, A., Arnaud, E., Aubin, S., \& Yeumo, E. D. 2016. AgroPortal : an open repository of ontologies and vocabularies for agriculture and nutrition data, (February 2017).

Kadiyala, S., Harris, J., Headey, D., Yosef, S., \& Gillespie, S. 2014. Agriculture and nutrition in India : Mapping evidence to pathways Agriculture and nutrition in India: mapping evidence to, (August). https://doi.org/10.1111/nyas.12477

Mayne, J., and Johnson, N. 2015. Using theories of change in the CGIAR Research Program on Agriculture for Nutrition and Health. Evaluation, 21(4): 407-428.

https://doi.org/10.1177/1356389015605198

Mayne, J., and Johnson, N. 2016. Using theories of change in the CGIAR Research Program on Agriculture for Nutrition and Health. Evaluation, 21(4): 407-428. Women's https://doi.org/10.1177/1356389015605198

Musker, R., and Schaap, B. 2018. Global Open Data in Agriculture and Nutrition (GODAN) initiative partner network analysis [ version 1 ; referees: awaiting peer review ], (0). https://doi.org/10.12688/f1000research.13044.1

Ogutu, S. O., Theda, G., \& Qain, M. 2020. Agricultural Commercialisation and Nutrition in Smallholder Farm Households. Journal of Agricultural Economics, 71: 534-555. https://doi.org/10.1111/1477-9552.12359

Poole, N., Echavez, C., and Rowland, D. 2018. Are agriculture and nutrition policies and practice coherent? Stakeholder evidence from Afghanistan. Food Security.

Rao, N., Gazdar, H., Chanchani, D., and Ibrahim, M. 2018. Women' s agricultural work and nutrition in South Asia: From pathways to a crossdisciplinary, grounded analytical framework Women' $\mathrm{s}$ agricultural work and nutrition in South Asia: From pathways to a crossdisciplinary, grounded analytical framework. Food Policy, 82:50-62. https://doi.org/10.1016/j.foodpol.2018.10.014

Rao, N., Gazdar, H., Chanchani, D., and Ibrahim, M. 2019. Women's agricultural work and nutrition in 
South Asia: From pathways to a crossdisciplinary, grounded analytical framework. Food Policy, 82(November), 50-62. https://doi.org/10.1016/j.foodpol.2018.10.014

RDW, K., S, M., R, R., K, S., D, G., R, A., ... KP Jr, W. 2018. Pathways from Agriculture-to-Nutrition: Design and Conduct of the National PoSHAN Surveys of Nepal. Journal of Food Security, 6(2), 79-89. https://doi.org/10.12691/jfs-6-2-5
Turner, R., Hawkes, C., Waage, J., Ferguson, E., Haseen, F., Hussein, J., ... Mcneill, G. 2014. Agriculture for improved nutrition: The current research landscape, (August). https://doi.org/10.1177/156482651303400401

Yosef, S., Jones, A. D., Chakraborty, B., and Gillespie, S. 2015. Agriculture and nutrition in Bangladesh: Mapping evidence to pathways. Food and Nutrition Bulletin, 36(4), 387-404.

https://doi.org/10.1177/0379572115609195.

Citation: Rubeka I. 2021. Conceptualizing Agri Nutri Information Framework for Mitigating Nutrition Security Challenges of India: A much needed approach for Nutrition Security. International Journal of Agricultural and Applied Sciences, 2(2):1-7. https://doi.org/10.52804/ijaas2021.221

Copyright: ( ) Rubeka I. 2021. Creative Commons Attribution 4.0 International License. IJAAS allows unrestricted use, reproduction, and distribution of this article in any medium by providing adequate credit to the author(s) and the source of publication. 